American Journal of Pharmaceutical Education 2019; 83 (1) Article 7503.

\title{
COMMENTARY
}

\section{Curiosity and Knowledge are Vital Components of Curricular Reform}

\author{
Daniel R. Malcom, PharmD \\ Sullivan University College of Pharmacy, Louisville, Kentucky \\ Associate Editor, American Journal of Pharmaceutical Education, Arlington, Virginia
}

Submitted December 31, 2018; accepted January 15, 2019; published February 2019.

Keywords: curricular reform; curiosity; knowledge; higher education; epistemic curiosity

\begin{abstract}
“Google can answer anything you want, but it can't tell you what you ought to be asking."

- Ian Leslie, from Curious: The Desire to Know and Why Your Future Depends On It
\end{abstract}

As a preceptor for a critical care inpatient hospital experience, I see many students in their final year struggle to answer clinical questions using their drug information resources. One of my most recent students became flustered after a particular round of questions and stated, "You want what's in here," holding her mobile device, "to be in here," pointing to her head. While the expectation of a pharmacist (and student pharmacist) is not to have the entire breadth and depth of drug information memorized verbatim, the student's response brings up a very interesting dilemma facing both practicing pharmacists and learners alike. Pharmacists are drug information experts; therefore, they are expected to know a great deal of information about a wide variety of medications, yet this information is theoretically available and easily accessible to everyone. So, what, then is the role of the pharmacist, and how do we prepare students to take on this role? And how can we ensure curricular reform efforts continue to produce practice-ready pharmacists?

The answers to these questions are not simple, and can be controversial, but they are also not so prohibitively complex that they should prevent thorough analysis and discussion. At the core of a pharmacist's role is the provision of knowledge to patients, caregivers, families, and other health care providers, all of whom look to pharmacists as the medication experts. ${ }^{1}$ Thus, ensuring that learners acquire that knowledge (by whatever means) is and should be a top priority for educators. However, an additional critical, if underappreciated element is "curiosity," or the innate desire to push beyond simple answers and to understand why background information interrelates and to develop context. ${ }^{2,3}$ Without context and a desire to be curious about a fact retrieved for a quick re-

Corresponding Author: Daniel Malcom, Sullivan University College of Pharmacy, 2100 Gardiner Ln., Louisville, KY 40205. Tel: 502-413-8969. Email: dmalcom@sullivan.edu sponse to a question becomes analogous to a person providing a phone number: entering it into short-term memory for immediate use, but having that knowledge depart just as rapidly. Students who learn skills without the prerequisite knowledge to build a foundational structure of knowledge risk learning the act of knowledge provision without really understanding how and why that knowledge fits into the overall picture of patient care.

The opening quote speaks to the challenge facing this generation of learners and educators. How do we encourage learning for the sake of learning when an abundance of answers, facts, and data are available with a click? Enhancing and stimulating curiosity is one important method to foster this type of learning. ${ }^{4}$ Author Ian Leslie, in his book titled, Curious: The Desire to Know and Why Your Future Depends On It, describes the concepts of "diversive" and "epistemic" curiosity. ${ }^{5}$ While the concept of curiosity is certainly familiar on the surface to most people, the psychological constructs of diversive and epistemic curiosity point to two important, yet disparate, ideas about the purpose of curiosity.

Diversive curiosity is the basic desire for something new or different, and it is analogous to a puzzle in that a puzzle has a predetermined solution that is unknown at the beginning and takes time to fully realize. Every headline to a news article is designed to evoke diversive curiosity and encourage someone to read or to click, which then leads to finding a solution to the puzzle and satisfying the diversive curiosity. Think of looking up the dose of a drug as a pharmacy-related example of this type of curiosity. Like a puzzle, the pieces (or facts) are available and relatively constant, but they need to be obtained (or arranged) by the person seeking them.

Epistemic curiosity, however, is the need to gather new knowledge expected to stimulate intellectual interest (ie, gaining knowledge for the sake of learning). Derived from "epistemology," or the study of knowledge and knowledge gathering, epistemic curiosity is more analogous to a mystery, in which many facts are unknown and there is no certainty of an absolute answer. From Leslie's 


\section{American Journal of Pharmaceutical Education 2019; 83 (1) Article 7503.}

book, "If diversive curiosity is the flash and splash of novel stimuli, epistemic curiosity is a path you want to keep traveling down, even when the road is bumpy." 5 In a pharmacy context, one way to characterize epistemic curiosity is to inquire into what motivated the patient to ask the question (which the patient did not directly ask you to do), and perhaps finding that something more complex is happening which may change the pharmacist's recommendation. Pharmacists need epistemic curiosity and its associated thought processes to provide highquality patient care. Any efforts to expand the scope of practice through creativity, innovation, and entrepreneurship also require epistemic curiosity.

Curricular reform is happening throughout higher education and has been discussed extensively in this publication and others with specific reference to changes in pharmacy. ${ }^{6-10}$ Generally, curricula are moving toward "experiential" types of learning (eg, clinical reasoning cases, simulations) and away from traditional "directional" (ie, faculty to student) classroom learning. Significantly more focus is being placed on doing something over acquiring knowledge. The shift toward experiential learning comes with its own unique challenges, including ensuring oversight and completeness (ie, all topics are seen, taught, or learned). ${ }^{11,12}$ Student pharmacists are held accountable for knowing a significant amount of medication information, even if the student was never exposed to a patient with the particular disease state. This approach relies heavily on the student to be self-directed in their learning, and it will require programs to assess not just achievement of educational outcomes but also the student's ability to learn independently.

Another concurrent issue is the concept of "baseline knowledge" which is the core knowledge required for a student (or other learner) to be properly prepared to learn from experiences. From a purely "experiential" standpoint, one could be taught the mechanics of how to perform nearly any task. But, without appropriate baseline knowledge, the experience is simply "time spent doing" rather than a practical application of knowledge. Additionally, it would be difficult to anticipate problems or proactively develop solutions without this appropriate baseline knowledge. We call this type of preparation being ready to enter advanced pharmacy practice experiences ("APPE-ready") in a pharmacy education context, but it goes further than simply being prepared for the final year of a pharmacy program. ${ }^{13}$ Knowledge acquisition is a lifelong endeavor, a balance struck throughout one's career of learning through traditional means (reading, watching, etc.) and learning through experience. Epistemic curiosity allows us to anticipate problems and acquire knowledge to solve or even prevent those problems from occurring.
No educator or pharmacy program can create a big enough "gap" to fill (meaning, diversive curiosity) for learners that exactly mimics everything seen in pharmacy practice. Rather, we rely on students to have epistemic curiosity to use the models provided by educators as constructs to apply to other situations, gradually learning to anticipate and appropriately manage problems.

Given the current landscape of curricular reform efforts and the challenges facing educators and students regarding availability of information, assessing and enhancing epistemic curiosity should be a priority for pharmacy programs. ${ }^{14,15}$ This approach will require further research into best curricular and co-curricular practices, but it should also focus on ensuring that students are "primed" with the right knowledge at various experiential stages to optimize the learning environment. ${ }^{16,17}$ Because this type of education requires more selfdirected students as aforementioned, change will likely be needed beyond the curriculum into all aspects of pharmacy programs including admissions, student services, and assessment. Still, the first step is curricular reform. As educators, we need to encourage students to exercise their epistemic curiosity whenever possible and teach them to understand that while finding the answers can be elusive, asking the right questions is the most important place to start.

\section{REFERENCES}

1. Waterfield J. Is pharmacy a knowledge-based profession? Am J Pharm Educ. 2010;74(3):Article 50.

2. Ellaway RH. When I say. . .epistemic curiosity. Med Educ. 2014;48(2):113-4.

3. Kidd C, Hayden BY. The Psychology and Neuroscience of Curiosity. Neuron. 2015;88(3):449-60.

4. Dann R. Be curious: understanding 'curiosity' in contemporary curriculum policy and practice. Education 3-13. 2013;41(6):557-561.

5. Leslie I. Curious: The Desire to Know and Why Your Future Depends On It. New York, NY: Basic Books; 2014.

6. McLaughlin JE, Bush AA, Rodgers PT, et al. Exploring the requisite skills and competencies of pharmacists needed for success in an evolving health care environment. Am J Pharm Educ. 2017;81 (6):Article 116.

7. Crass RL, Romanelli F. Curricular reform in pharmacy education through the lens of the flexner report of 1910. Am J Pharm Educ. 2018;82(7):Article 6804.

8. Islam MA, Talukder RM, Taheri R, Blanchard N. Integration of Basic and Clinical Science Courses in US PharmD Programs. Am J Pharm Educ. 2016;80(10):Article 166.

9. Mawdsley A, Willis S. Exploring an integrated curriculum in pharmacy: Educators' perspectives. Curr Pharm Teach Learn. 2018;10(3):373-381.

10. Trygstad T. Payment reform meets pharmacy practice and education transformation. N C Med J. 2017;78(3):173-176. 11. Assemi M, DiVall MV, Lee K, Sy E, O’Sullivan T. Quality assurance and improvement practices of experiential education programs within US schools of pharmacy. Am J Pharm Educ. 2018. Article 6582. 12. Frail CK, Chapman SA, Jolowsky C, Moon JY, Philbrick AM. Supporting quality in experiential education through enhanced 


\section{American Journal of Pharmaceutical Education 2019; 83 (1) Article 7503.}

faculty engagement. Curr Pharm Teach Learn. 2017;9(6):962965.

13. Accreditation Council for Pharmacy Education. Accreditation standards and key elements for the professional program in pharmacy leading to the doctor of pharmacy degree ("Standards 2016"). https:// www.acpe-accredit.org/pdf/Standards2016FINAL.pdf. Accessed December 19, 2018.

14. Litman JA, Spielberger CD. Measuring epistemic curiosity and its diversive and specific components. J Pers Assess. 2003;80(1):75-86.
15. Oudeyer PY, Gottlieb J, Lopes M. Intrinsic motivation, curiosity, and learning: Theory and applications in educational technologies. Prog Brain Res. 2016;229:257-284.

16. Eastwood JL, Koppelman-White E, Mi M, Wasserman JA, Krug Iii EF, Joyce B. Epistemic cognition in medical education: a literature review. Int J Med Educ. 2017;8:1-12.

17. Sternszus R, Saroyan A, Steinert Y. Describing medical student curiosity across a four year curriculum: An exploratory study. Med Teach. 2017;39(4):377-382. 